\title{
Whistle Blowing: A Message to Leaders and Managers \\ Comment on "Cultures of Silence and Cultures of Voice: The Role of Whistleblowing in Healthcare Organizations"
}

\section{Edgar H. Schein*}

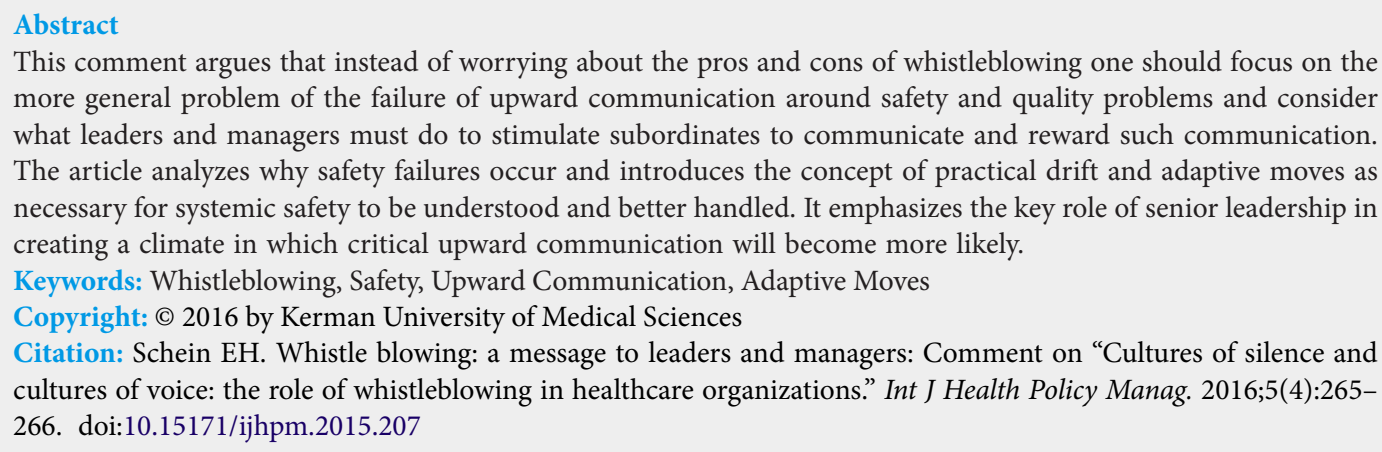

This comment argues that instead of worrying about the pros and cons of whistleblowing one should focus on the more general problem of the failure of upward communication around safety and quality problems and consider what leaders and managers must do to stimulate subordinates to communicate and reward such communication. The article analyzes why safety failures occur and introduces the concept of practical drift and adaptive moves as necessary for systemic safety to be understood and better handled. It emphasizes the key role of senior leadership in creating a climate in which critical upward communication will become more likely.

Keywords: Whistleblowing, Safety, Upward Communication, Adaptive Moves

Copyright: @ 2016 by Kerman University of Medical Sciences

Citation: Schein EH. Whistle blowing: a message to leaders and managers: Comment on "Cultures of silence and cultures of voice: the role of whistleblowing in healthcare organizations." Int J Health Policy Manag. 2016;5(4):265266. doi:10.15171/ijhpm.2015.207

Article History:

Received: 7 November 2015 Accepted: 27 November 2015 ePublished: 29 November 2015

View Video Summary

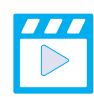

*Correspondence to:

Edgar H. Schein

Email: scheine@comcast.net
$\mathrm{T}$ The problem that Mannion and Davies ${ }^{1}$ identify can be stated as the intrinsic difficulty of upward communication across hierarchic or professional status boundaries. It is in the nature of hierarchy and status to assume that the person in higher authority now has the license to tell others what to do. It is the "divine right of managers" to tell rather than to ask and listen, and to perceive whistle blowers as malcontents and trouble-makers, "wimps" who see safety hazards everywhere, or as people who see only the bad things in the organization.

When managers do have to listen because the problem has blown up into a scandal, they immediately see it as "an exception," try to "identify and get rid of the few bad apples in the barrel who are doing things wrong," and vehemently remind everyone of all the good things that are going on. There is little appetite in leadership to question their own position, to make themselves vulnerable by acknowledging that subordinates may know things and may see systemic things that are critical to improving the overall functioning of the organization. Leaders prefer root cause analysis and to locate people to blame rather than examining the systemic forces at work that cause bad things to happen from time to time. This reluctance to ask and listen goes on in all organizations because we have evolved in the United States a culture of leadership and management built around the "divine right of managers."

To "fix" this problem will require a series of what I refer to as "adaptive moves." The first of these is to take a different approach to the analysis of scandals and accidents such as patient deaths. Instead of looking for root causes and people to blame, assume that people acted in good faith based on their assessment of the situation at the moment. Accept what safety experts have shown over and over again - that actions and ultimate results are "over-determined," that what we do and what ultimately happens always has multiple causes. Many of the examples in the recent book Case Studies in Patient Safety show how patient deaths result from the complex interactions of doctors, nurses, and patients in surgery, intensive care, normal hospitalization and home care, not some discrete action that might warrant whistle blowing. ${ }^{4}$

Work in real situations such as in the hospital will always experience some amount of "practical drift" - a deviation from desired behavior or what the rules require because of local circumstances that make it necessary for people to use their own judgment and sometimes choose to break the rule to "get the job done." For example, in a power company, electrical workers broke the rule that "you must always wear your safety glasses" when they found, on hot humid summer days, that they could not do their work because their glasses steamed up. The adaptive move here was to redesign the glasses instead of punishing the workers for breaking the rule. A hospital example was a resident going to the pharmacy in the middle of the night to mix a dose of medicine that a cancer patient had not been given. The justification for this illegal and dangerous action was "professional duty" to the patient. The point is that practical drift can be harmful and reflect negligence or actually helpful if it is motivated by sense of obligation. In either case, what is missing that management must address, is the upward communication of these events and correlated examples of "near misses" and "close calls" so that the system can be better understood and adaptive moves made.

The main adaptive move would be to ask senior management to become more mindful of how they react to subordinate comments about safety or quality. Do they welcome inputs from subordinates, do they encourage them, reward them, and acknowledge their importance, or do they feel that "it is the subordinate's 'professional responsibility' to speak up 
whenever they see something amiss" and otherwise assume that no news is good news. When I have spoken to subordinates I find all too often that their view is quite different. They do not feel obligated to tell the boss when they see something hazardous or amiss for any of the following reasons: (1) "The last time I tried to tell the boss something, he was too busy;" (2) "He listened and said he would take care of it but never did anything;" (3) "He said 'don't bring me problems unless you have a solution;" and (4) "He said not to worry about it, it is not a serious issue."

Hopefully not every boss creates such a negative climate, but even in very safe organizations when I ask subordinates, "Do you tell your boss when you see something wrong?" I am shocked by how many of them say without hesitation, "Of course not." Every organization should have some neutral parties go around the organization whose role is to ask various employees this question and provide the feedback to the managers. There is deep wisdom in the Arabian Nights story that the Caliph of Bagdad periodically put on beggar's clothes and went down into the city to find out what was really going on because his immediate subordinates clearly had no incentive to tell him the truth.

Another adaptive move is to learn to pay attention to what in the safety literature are called "weak signals." ${ }^{\circ}$ Blatant problems that end up with whistle blowing or fatal accidents are usually preceded by small problems that are detected but are less likely to be reported or taken seriously. For example, tensions between surgeons and nurses that a new nurse might observe immediately would be examples of such weak signals that are often ignored. Minor deviations from procedures, the practical drift referred to above, would be another example. An interesting adaptive move by a manager would be to bring her subordinates together just to identify and discuss the implications for safety and quality of various weak signals that they detect.

The most important adaptive move by the leader or the higher status person is to "personalize" his relationship with the subordinates, get to know them as individuals rather than as occupants of technical or professional roles.
In my forthcoming book "Humble Consulting" ${ }^{3}$ I propose that unless we personalize relationships across hierarchical boundaries, the subordinate will never feel entirely safe in bringing up negative information. Mutual trust and openness are crucial components of a working relationship yet all too often "professional distance" actually works against being open and trusting. This does not imply intimacy or even close friendship but the acceptance of another human being with whom we are dealing as a total person, welcoming openness around work-related issues rather than displaying impatience or irritation when someone speaks up.

It is the combination of "professional distance" and the attitude of the "divine right of managers" that ultimately create the conditions that cause some employees to become whistleblowers. The solution is to create conditions where there is no need for whistleblowers because the degree of personalization, openness and trust causes undesirable behavior to be noticed, reported, and dealt with as a problem of systemic learning rather than blame and punishment.

Ethical issues

Not applicable.

Competing interests

The author declares that he has no competing interests.

Author's contribution

EHS is the single author of the manuscript.

\section{References}

1. Mannion R, Davies HT. Cultures of silence and cultures of voice: the role of whistleblowing in healthcare organizations. Int J Health Policy Manag. 2015;4(8):503-505. doi:10.15171/ ijhpm.2015.120

2. Schein EH. Humble Inquiry. San Francisco: Berrett/Kohler; 2013.

3. Schein EH. Humble Consulting. San Francisco: Berrett/Kohler; 2016. [In Press].

4. Johnson J, Haskell H, Barach P. Case studies in patient safety. Burlington, MA: Jones \& Bartlett Learning; 2016.

5. Snook SA. Friendly Fire. Princeton University Press; 2000.

6. Gerstein M. Flirting with Disaster. New York: Union Square Press; 2008. 